Asian J. Med. Biol. Res. 2018, 4 (3), 274-278; doi: 10.3329/ajmbr.v4i3.38466

\author{
Asian Journal of \\ Medical and Biological Research \\ ISSN 2411-4472 (Print) 2412-5571 (Online) \\ www.ebupress.com/journal/ajmbr
}

\title{
Article \\ Prevalence of gestational diabetes and associated risk factors
}

Jayati Debnath $^{1}$, SumonTalukder ${ }^{2}$, Md. Shajadul Islam ${ }^{3}$, Md. Shafiqul Islam Khan ${ }^{3 *}$, Sadman Sakib Sabuj ${ }^{2}$ and Dilruba Easmin Jhorna ${ }^{1}$

${ }^{1}$ Department of Human Nutrition and Dietetics, Faculty of Nutrition and Food Science, Patuakhali Science and Technology University, Bangladesh

${ }^{2}$ Department of Community Health and Hygiene, Faculty of Nutrition and Food Science, Patuakhali Science and Technology University, Bangladesh

${ }^{3}$ Department of Food Microbiology, Faculty of Nutrition and Food Science, Patuakhali Science and Technology University, Bangladesh

*Corresponding author: Md. Shafiqul Islam Khan, Associate professor, Department of Food Microbiology, Faculty of Nutrition and Food Science, Patuakhali Science and Technology University, Bangladesh. Phone: +8801712115973; E-mail: msikhan312@yahoo.com

Received: 07 September 2018/Accepted: 22 September 2018/ Published: 30 September 2018

\begin{abstract}
This study was conducted to know prevalence of gestational diabetes and associated factors. A cross sectional data was collected from the pregnant mothers from a hospital of Barisal city, Bangladesh. It was revealed that 5\% of the interviewed mothers suffer from diabetes. Among 100 participants, 58\% were in 20-30 years age group and $68 \%$ patients married within 21-25 years old. Near about half (51\%) of mothers had more than $60 \mathrm{Kg}$ body weight. Maximum (48\%) patients passed their secondary education and $78 \%$ were jobless. More than half (56\%) of the patient's family monthly earned 10000-20000 BD Tk. Among the mothers, 15\% had the family history of diabetes. Correlation matrix revealed that, body weight, and blood pressure were positively associated with sugar level. Gestational age $(\mathrm{P}=0.04261)$ and diastolic blood pressure $(\mathrm{P}=0.018764)$ were significantly associated with the RBS of pregnant mothers. More study should be conducted to explore the accurate prevalence and practices of diabetic patients in the study area.
\end{abstract}

Keywords: gestation; diabetes; factors

\section{Introduction}

Gestational diabetes mellitus (GDM) has been increasing globally (Leng, 2015). It has negative short-term and long-term outcomes both for mothers and their future offspring (Metzger, 2008). The prevalence varies widely according to location, diets and socio-economic status (Begum et al., 2017). In a recent study in Bangladesh a higher prevalence of diabetes was found in urban (8.1\%) compared with rural populations (2.3\%) (Hussain, 2005). But, according to World Health Organization (WHO) 1999 and WHO 2013 diagnostic criteria respectively, it was alarmingly high (36.6\% and 40.9\% respectively) in Bangladeshi population (Hasanat, 2016). More research should be conducted due to inconsistency of previous results in different areas of Bangladesh. Like other diseases GDM associated with some risk factors. Hasanat (2016) found its association with age and body mass index (BMI). Also, the highest risk factors for GDM are high maternal age, family history of T2DM, being overweight prior to pregnancy (Abrams, 1988), excessive gestational weight gain, and a past history of GDM/glucose intolerance (Cianni, 2003). There are limited studies conducted about GDM in the study area. Moreover, widely dissimilar rates observed in studies in different places necessitated for quantifying prevalence as well as risk factors associated with it. Varying socio economic condition and food habit in this area may influence the prevalence and risk factors. The study was, therefore conducted to know the actual prevalence and risk factors diabetes during pregnancy in the study area. 
2. Materials and Methods

\subsection{Study design}

We conducted the study among the mothers came for antenatal care at St's Annes Medical Center in Barisal city, Barisal. We collected a cross sectional data from July 2017 to December 2017 to know prevalence of gestational diabetes. We also assessed the associated factors related to diabetes in the study area. We considered all those mothers who were pregnant at our study time. We enrolled total 100 persons who met our case definition. We used a pre- structured questionnaire to collect data. We also measured the Random Blood Sugar (RBS) and weight of patients. We interviewed patients directly for collecting data. We obtained written consent from the study participants to participate in this study.

\subsection{Measurement of BMI and RBS}

We measured Height with a portable Harpendenstadiometer (Holtain Ltd, London, UK). We recorded parameters while the participant stood, without shoes, on a horizontal flat plate attached to the base of the stadiometer with heels together and fully stretched upward with the head in the Frankfurt plane as described by Kitange (1994). BMI was calculated using the formula weight $/$ height ${ }^{2}$. It was categorized according per Yazdani (2012): underweight $\left(<20 \mathrm{~kg} / \mathrm{m}^{2}\right)$, normal $\left(20-24.9 \mathrm{~kg} / \mathrm{m}^{2}\right)$, and overweight $\left(\geq 25 \mathrm{~kg} / \mathrm{m}^{2}\right)$. We analyzed RBS with Glucolidder, China and categorized as diabetic patient who had greater than 7.8 mmole/L RBS according to Dutta (2009).

\subsection{Ethics approval}

The research was conducted in accordance with the declaration of Helsinki. Written consent was obtained from the participants before collecting data. Participants were informed of their rights to withdraw from the study at any stage.

\subsection{Statistical analysis}

We performed descriptive analysis to summarize the demographic characteristics of studied participants and their socioeconomic factors. Correlation matrix was done to know the association of GDM outcome with other dependent variables. We used SPSS version 16 to analyze the data and considered 5\% level of significance.

\section{Results}

Table 1 represents the demographic characteristic of gestational diabetic patients. Among 100 participants, maximum 58\% were in 20-30 years age group and around $40 \%$ were more than 30 years old. Highest parts of mothers $(68 \%)$ married within 21-25 years old. More than 50\% mothers had over $60 \mathrm{~kg}$ body weight. $88 \%$ patients followed Muslim religion and $12 \%$ patients followed Hindu religion. Maximum (48\%) patients passed their secondary education. Only $22 \%$ patients had employment where $78 \%$ were jobless. More than half (56\%) of the patient's family income was 10000-20000 BD Tk. Patients with family history of diabetes were $15 \%$.

Table 1. Demographic characteristic of gestational diabetic patient.

\begin{tabular}{llll}
\hline Parameter & Category & Frequency & Percentage \\
\hline Age & $<20$ & 3 & $3 \%$ \\
& $20-30$ & 58 & $58 \%$ \\
Age of marry & $>31$ & 39 & $39 \%$ \\
& $16-20$ & 10 & $10 \%$ \\
Body weight & $21-25$ & 68 & $68 \%$ \\
& $26-30$ & 22 & $22 \%$ \\
Religion & $<50$ & 15 & $15 \%$ \\
& $50-60$ & 34 & $34 \%$ \\
Education & $>60$ & 51 & $51 \%$ \\
& Muslim & 88 & $88 \%$ \\
& Hindu & 12 & $12 \%$ \\
Employment status & Illiterate & 7 & $7 \%$ \\
Family income & Primary & 10 & $10 \%$ \\
& Secondary & 48 & $48 \%$ \\
& Higher and Above & 35 & $35 \%$ \\
& Yes & 22 & $22 \%$ \\
Family history of diabetes & No & 78 & $78 \%$ \\
& $<10000$ & 15 & $15 \%$ \\
& $10000-20000$ & 56 & $56 \%$ \\
& $21000-30000$ & 22 & $22 \%$ \\
& $>30000$ & 7 & $7 \%$ \\
& Yes & 15 & $15 \%$ \\
\end{tabular}


Table 2. Physiological characteristic of gestational diabetic patient.

\begin{tabular}{llll}
\hline Parameter & Category & Frequency & Percentage \\
\hline Body Mass Index (BMI) & $<18.5$ & 2 & $2 \%$ \\
& $18.5-24.9$ & 58 & $58 \%$ \\
& $25-29.9$ & 36 & $36 \%$ \\
Level of sugar & $>30$ & 4 & $4 \%$ \\
& $>7.8 \mathrm{mmol} / \mathrm{L}$ & 5 & $5 \%$ \\
Gestational age & $4.4-7.8 \mathrm{mmol} / \mathrm{L}$ & 73 & $73 \%$ \\
& $<4.4 \mathrm{mmol} / \mathrm{L}$ & 22 & $22 \%$ \\
Hemoglobin & $13-26$ & 35 & $35 \%$ \\
& $27-40$ & 65 & $65 \%$ \\
BP (sysytolic) & $<10.9$ & 48 & $48 \%$ \\
BP (Diastolic) & $\geq 11$ & 51 & $51 \%$ \\
& $\leq 120$ & 92 & $92 \%$ \\
& $\geq 120$ & 8 & $8 \%$ \\
& $\geq 80$ & 98 & $98 \%$ \\
\hline
\end{tabular}

Table 3. Correlation between diabetes other variables.

\begin{tabular}{lll}
\hline & Correlation coefficient & P value \\
\hline Age & -0.03547 & 0.726076 \\
B W & 0.209405 & 0.056531 \\
Systolic pressure & 0.019185 & 0.849739 \\
Diastolic Pressure & 0.234676 & $0.018764 * *$ \\
Gestational age & 0.05685 & $0.04261^{* *}$ \\
$\mathrm{Hb}$ & 0.195109 & 0.052954 \\
\hline
\end{tabular}

$* * 5 \%$ level of significance.

Table 2 represents physiological characteristic of gestational diabetic patient. Maximum patients (58\%) had normal BMI with range $18.5-24.9$ and only $2 \%$ had the BMI < 18.5. Only 5\% patients had random blood sugar more than $7.8 \mathrm{mmol} / \mathrm{l}$ where about three fourth $(73 \%)$ of the patients had normal random blood sugar level. About two third $(65 \%)$ of women were in third trimester. Almost half $(48 \%)$ of the mothers were anemic. More than $90 \%$ diabetic patients had normal blood pressure.

Table 3 represents correlation between diabetes and other variables. Body weight, $\mathrm{Hb}$ and blood pressure were positively associated with sugar level. Age of mothers was inversely associated with level of sugar. Gestational age $(\mathrm{P}=0.04261)$ and diastolic blood pressure $(\mathrm{P}=0.018764)$ were significantly associated with the RBS of pregnant mothers.

\section{Discussion}

Present study was to find out the prevalence of GDM and its risk factors. In this study we found that the prevalence of diabetic patients was 5\%. Almost similar result found in Iran (4.8\%) and Turkmenistan (6.3\%) (Gundogan et al., 2013). Another study by Zargar et al. (2004) reported the overall prevalence of GDM was lower (3.8\%) in Kashmir, India. On the contrary, it was a bit higher 6.94\% in Jummu, 7.1\% in Haryana, 7.3\% in Maharastra, 6.8\% in Tehran and 8.3\% in Rwanda (Wahi et al., 2011; Rajput et al., 2013; Begum et al., 2017; Garshasbi et al., 2008; Niyibizi et al., 2016). In Bangladesh, the prevalence of GDM was found 9.7\% (Jesmin et al., 2014). The variation in the prevalence of GDM could be due to local, cultural context and other factors as ethnicity, education and anthropometry of mothers (Wahi et al., 2011 and Rajput et al., 2014). In present study, $58 \%$ of GDM women were age ranged from 20-30 years old. Gracelyn and Saranya (2016) found similar $62.71 \%$ women with GDM were 26-30 years. Sreekanthan et al. (2014) found 75\% of GDM women were above 25 years of age. Kalyani et al. (2014) found 56\% of GDM females were more than 25 years of age. Kalra et al. (2013) reported pregnant women below 25 years of age are less prone to develop GDM. Significant relationship was noted between age and GDM. It may be due to increasing educational level and working opportunities. We found diabetic patients $20 \%$ and $80 \%$ in second and third trimester respectively. GDM generally develops during the second and third trimester of the pregnancy, because insulin resistance and diabetogenic effect of pregnancy hormones will be maximum in this period (Gracelyn and Saranya, 2016). In this research diastolic 
blood pressure was significantly associated with gestational diabetics. Vembergre et al. (2002) noted that pregnancy-induced hypertension appears to be linked to the level of glucose intolerance during pregnancy. Women with hypertension had a twofold increased risk of GDM compared with women with normal BP. Gonsalves et al. (2005) had also mentioned that women with gestational hyperglycemia and GDM have higher risk of hypertension.

\section{Conclusions}

The prevalence of diabetes has been rising worldwide, which adversely affects maternal and fetal outcomes. In this study gestational diabetes was associated with gestational age and diastolic blood pressure. Late pregnancy should be paid more attention to reduce the ill effects of GDM on mother and future child. Because, insulin resistance became maximum in this period. Blood pressure of pregnant mother should be monitored regularly as it is associated with increased prevalence of diabetes. Pregnancy-induced hypertension together with hyperglycemia may lead to bad consequences both mother and child.

\section{Conflict of interest}

None to declare.

\section{References}

Abrams B and J Parker, 1988. Overweight and pregnancy complications. International Journal of Obesity, 12: 293-303.

Begum P, DR Shaha and KM Walid, 2017. Gestational diabetes mellitus and associated risk factors in patients attending diabetic association medical college hospital in Faridpur. J. Enam Med. Col., 7: 126-133.

Cianni G, L Volpe, C Lencioni, R Miccoli, I Cuccuru, A Ghio, K Chatziagnostou, P Botone, G Teti, PS Del and L Benzi, 2003. Prevalence and risk factors for gestational diabetes assessed by universal screening. Diabetes Research and Clinical Practice, 62: 131-137.

Dutta DC, 2009. Text book of obstetrics. $5^{\text {th }}$ Ed. Jay pee brothers medical publishers; Hiralalkonar. India. pp. 281.

Garshasbi A, S Faghihzadeh, MM Naghizadeh and M Ghavam, 2008. Prevalence and risk factors for gestational diabetes mellitus in Tehran. Journal of Family and Reproductive Health, 2: 75-80.

Gonsalves LC, MR Silva, AJC Pera, LV de Silveria, CR Padovani and WP de Pimenta, 2005. Hypertension after gestational hyperglycaemia. Arq. Bras. Endocrinol. Metabol., 49: 265-70.

Gracelyn LJ and N Saranya, 2016. Prevalence of gestational diabetes mellitus in antenatal women and its associated risk factors. Int. J. Reprod. Contracept. Obstet. Gynecol., 5: 285-91.

Gundogan K, F Bayram, V Gedik, C Erem, C Arsalan and A Hachihasanoglu, 2013. Metabolic syndrome prevalence according to ATP III and IDF criteria and related factors in Turkish adults. Arch. Med. Sci., 9: $243-253$.

Hasanat MA, 2016. Gestational diabetes mellitus- experience in BSMMU, Bangladesh. J Diabetes Metab., 7: 8 (Suppl).

Hussain A, MA Rahim, A Khan, SM Ali and S Vaaler, 2005. Type 2 diabetes in rural and urban population: diverse prevalence and associated risk factors in Bangladesh. Diabet. Med., 22: 931-936.

Jesmin S, S Akter, H Akashi, A Al-Mamun, MA Rahman, MM Islam, 2014. Screening for gestational diabetes mellitus and its prevalence in Bangladesh. Diabetes Research and Clinical Practice, 103: 57-62.

Kalra P, CP Kachhwaha and HV Singh, 2013. Prevalence of gestational diabetes mellitus and its outcome in western Rajasthan. Indian J. Endocr. Metab., 17: 677-80.

Kalyani KR, S Jajoo, C Hariharan and S Samal, 2014. Prevalence of gestational diabetes mellitus, its associated risk factors and pregnancy outcomes at a rural setup in Central India. Int. J. Reprod. Contracept. Obstet. Gynecol., 3: 219-224.

Kitange D, 1994. Adolescent health and nutrition. In: Proceedings of the National Maternal Nutrition Workshop; Mbagala, Dar es Salaam, Tanzania; January 11-15, 1993. Dar es Salaam: TFNC., pp. 145.

Leng J, P Shao, C Zhang, HTian, F Zhang and S Zhang, 2015. Prevalence of gestational diabetes mellitus and its risk factors in Chinese pregnant women: a prospective population-based study in Tianjin, China. PLoS ONE, 10: e0121029.

Metzger BE, LP Lowe, AR Dyer, ER Trimble, U Chaovarindr and DR Coustan, 2008. Hyperglycemia and adverse pregnancy outcomes. N. Engl. J. Med., 358: 1991-2002. 
Niyibizi JB, F Safari, JB Ahishakiye, JB Habimana, H Mapira and NC Mutuku, 2016. Gestational diabetes mellitus and its associated risk factors in pregnant women at selected health facilities in Kigali City, Rwanda. Journal of Diabetes Mellitus, 6: 269-276.

Rajput M, M Bairwa and R Rajput, 2014. Prevalence of gestational diabetes mellitus in rural Haryana: A community based study. Indian J. Endocrinol. Metab., 18: 350-354.

Rajput R, Y Yadav, S Nanada and M Rajput, 2013. Prevalence of gestational diabetes mellitus and associated risk factors at a tertiary care hospital in Haryana. Indian J. Med. Red., 137: 728-33.

Sreekanthan K, A Belicita, K Rajendran and A Vijayakumar, 2014. Prevalence of gestational diabetes mellitus in a medical college in South India: a pilot study. Indian Journal of Clinical Practice, 25: 342-347.

Vambergue A, MC Nuttens, P Goeusse, S Biausque, M Lepeut and P Fontaine, 2002. Pregnancy induced hypertension in women with gestational carbohydrate intolerance: the diagest study. Eur. J. Obstet. Gynecol. Reprod. Biol., 102: 31-35.

Wahi P, V Dogra, K Jandial, R Bhagat, R Gupta, S Gupta, A Wakhloo and J Singh, 2011. Prevalence of gestational diabetes mellitus and its outcomes in Jammu region. J. Assoc. Physicians India, 59: 227-230.

Yazdani S, Y Yosofniyapasha, BH Nasab, MH Mojaveri and Z Bouzari, 2012. Effect of maternal body mass index on pregnancy outcome and newborn weight. BMC Research Notes, 5: 34.

Zargar AH, MI Sheikh and M Bashir, 2004. Prevalence of gestational diabetes mellitus in Kashmiri women in Indian subcontinent. Diabetes Res. Clin. Pract., 66:139-45. 